\title{
Selvmordsforebygging i akutteam ved DPS
}

\author{
Ved Per Erik Sørum
}

\section{ABSTRACT}

Bakgrunn: Norske akutteam innen DPS benytter hovedsaklig høyskoleutdannet helsepersonell som hver dag reiser ut og møter potensielt selvmordstruede mennesker. En nasjonal klinisk retningslinje skal bidra til selvmordsforebygging og til at helsepersonell skal bli mer kompetente $\mathrm{i}$ håndtering av selvmordsrisiko.

Hensikt: Å utvikle kunnskap om hvordan de nasjonale retningslinjene har påvirket praksis i tre DPS akutteam.

Metode: Tre strukturerte kvalitative fokusgruppe intervjuer av tre ulike team ble utført for å generere data. Disse ble transkribert og analysert med systematisk tekstkondensering som er basert på fenomenologisk filosofi.

Resultater: Alle teamene kartla pasienters selv mordsrisiko i tråd med retningslinjene. Det var store variasjoner mellom teamene i forhold til grad av opplæring, dokumentasjon, ledelsesforankring, veiledning fra leger og psykologer, samt sikring i forhold til at kompetansekravet til vurdering av selvmordsrisiko var vurdert og ivaretatt. Konklusjon: De nasjonale retningslinjene var implementert i ulik grad i de tre teamene. Dette kan bero på ulik grad av ledelsesforankring, men også en manglende nasjonal definisjon på hvilken reell kompetanse høyskoleutdannet helsepersonell må ha for å vurdere selvmordsrisiko.

Background: Norwegian crisis resolution home teams consists of mainly college educated staff that treats potentially suicidal people. A national clinical guideline targets suicide prevention and for health professionals to become more competent in dealing with suicide risk.

Purpose: To develop knowledge of how the guidelines have affected such a practice in three teams. Method: Three structured focus group interviews with three different teams were conducted to generate data. These were transcribed and analyzed using systematic text condensation which is based on phenomenological philosophy.

Results: The teams screened all patients for suicide. There were large variations between teams in terms of degree of training, documentation, management support, guidance from doctors and psychologists, as well as securing that competence requirements for assessment of suicide risk was assessed and addressed.

Conclusion: The national guidelines were implemented to varying degrees between the teams.

This may be due to different levels of management support and lack of a national definition of what kind of competence college educated health professionals need in order to assess suicide risk.

\section{Akutteam ved DPS har en overvekt av høyskoleutdannet helseper- sonell som hver dag reiser ut og møter potensielt selvmordstruede mennesker. En mastergradsstudent har undersøkt hvordan nasjo- nale retningslinjer for forebygging av selvmord i psykisk helsevern har påvirket dette arbeidet i tre ulike team.}

Siden 1950-tallet har det i vestlige land vært en $\varnothing$ kende utvikling av tilbud som tilbyr hjemmebehandling og krisevurderinger. Dette er en del av utviklingen innen den såkalte deinstitusjonaliseringen, som har ført til nedbyggingen av de store asylene i hele den vestlige verden. (Johnson et al., 2008). I kjølvannet av dette har det vokst frem ulike former for team som arbeider med mennesker i psykiske og psykososiale kriser utenfor døgninstitusjonene (Burns, 2004; Johnson et al., 2008). Norske DPS akutteam har ikke eksistert lenge. I 2003 var det kun tre etablerte team (Ruud et al., 2006). Det ble i 2005 i tråd med opptrappingsplanen for psykisk helse fastslått i stortingsproposisjon 1 at alle landets DPS skulle ha akutteam innen utgangen av 2008. I 2010 var det etablert akutteam i 51 av 76 DPS i landet (Karlsson et al., 2011a). Det er store forskjeller mellom teamene på forhold som blant annet åpningstider, sammensetning av fagfolk, behandlingstid og henvisningsrutiner (Karlsson et al., 2011b). DPS akutteam arbeider mer med depresjon og selvmordsrelaterte kriser enn med for eksempel psykoser og rusrelaterte temaer (Hasselberg et al., 2011).

I 2010 tok 548 personer livet av seg i Norge (Statistisk sentralbyrå, 2010). Over $90 \%$ av utførte selvmord kan tilbakeføres til mennesker med psykisk lidelse (Cavanagh, 2003). I 2006 ga Helsedirektoratet ut en veileder med anbefalinger for ambulante akutteam: "Du er kommet til rett sted" (Sosial- og helsedirektoratet, 2006). Her slås det fast at teamene må være spesielt trent i forhold til å gjøre suicidalrisikovurderinger. I 2008 utga Helsedirektoratet Nasjonale retningslinjer for forebygging av selvmord i psykisk helsevern (Sosialog helsedirektoratet, 2008). Her anbe- fales det blant annet at alle som kommer i kontakt med psykisk helsevern bør kartlegges i forhold til selvmordsrisiko. Det skilles mellom kartlegging og vurdering av selvmordsrisiko. Helsedirektoratet mener at leger og psykologer er de to faggruppene som har kompetanse til å vurdere selvmordsrisiko. For annet helsepersonell må dette bero på en vurdering av de faglige kvalifikasjonene de reelt sett innehar. Statens Helsetilsyn skriver i sin årsmelding i 2006 at helsepersonell innen psykisk helsevern ikke har tilstrekkelig kompetanse til å utføre korrekte selvmordsrisikovurderinger og at virksomhetene mangler rutiner innen selvmordsforebyggende tiltak.

Denne artikkelen er basert på en mastergradsoppgave. Forskningssp $\varnothing$ rsmålet er: "Hvordan beskriver høyskoleutdannet helsepersonell i DPS akutteam selvmordsforebyggende praksis $i$ teamet etter at nasjonale retningslinjer for forebygging av selvmord i psykisk helsevern ble utgitt?" Hensikten med artikkelen er å belyse og utvikle kunnskap om, og eventuelt hvordan, de nasjonale retningslinjene har påvirket slik praksis i tre DPS akutteam.

\section{Metode}

Kvalitativ metode ble valgt fordi forskeren da făr nærhet til forskningsfeltet ved en interaksjon som er åpen mellom informant og forsker i stedet for avstand, og en empiri og eksplorerende (induktiv) måte å gå frem på, i stedet for en hypotese- og teoridrevet (deduktiv) måte (Tjora, 2010). Kvalitative studier er fortolkende med fokus på informantenes meningsdannelse, meningenes konsekvenser og opplevelse (Tjora, 2010). Dette er hensiktsmessig med tanke på problemstillingen hvor vi studerer ansattes beskrivelser av praksis. 
Fokusgruppeintervju ble benyttet fordi formen er spesielt godt egnet hvis vi фnsker å forske på et miljø hvor flere mennesker samhandler, og vi vil lære om deres synspunkter, holdninger og erfaringer (Malterud, 2011). Helsepersonell i DPS akutteam arbeider sammen, og det er på forhånd nærliggende å tro at de ansatte er vant til å drøfte utfordrende og vanskelige saker som selvmordsrisikohåndtering. Anbefalt antall deltagere i slike intervjuer er mellom fire og seks personer (Kitzinger, 1995). Det ble utført tre fokusgruppeintervjuer med tre forskjellige akuttteam ved tre ulike DPS hvor fire personer deltok i hvert intervju. Alle teamene hadde eksistert i flere år før retningslinjene kom i 2008. Alle intervjuer ble foretatt på akutteamenes arbeidsplass. Forskeren er selv ansatt i et DPS akuttteam, og et intervju foregikk i dette teamet. Alle intervjuer og analyser er utført av forfatteren alene.

Det ene teamet hadde opptaksområde i distriktet, mens de to andre var i storbyen. Alle de tre intervjuene varte i ca. halvannen time. Det ble foretatt et strategisk utvalg (Wibeck, 2010). Inklusjonskriterier var høyskoleutdannet helsepersonell som hadde vært i teamet i minst ett år før retningslinjene kom, og eksklusjonskriterier var leger og psykologer. Ledere deltok ikke. Hovedvekten av informanter var sykepleiere, som er representativt for norske faggrupper $\mathrm{i}$ akutteam (Muusmann/Agenda, 2008). Intervjuguiden var strukturert med punkter til diskusjon som har direkte tilknytning til de nasjonale retningslinjene.

Intervjuene ble tatt opp og transkribert ordrett. Analysen ble gjort i tråd med Malteruds (2011) systematiske tekstkondensering som er inspirert av Giorgis fenomenologisk analyse (Giorgi, A, 2009), hvor det søkes etter å erverve kunnskap om informantenes opplevde verden og erfaringer på et gitt område. Systematisk tekstkondensering deles inn i fire trinn. Først handler det om å skape et helhetsinntrykk. Deretter å identifisere enheter som er meningsbærende og systematisere disse under kodegrupper.

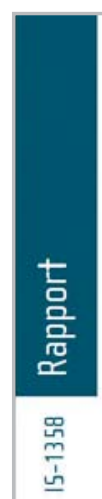

"DU ER KOMMET TIL RETT STED ........."

Ambulante akuttjenester ved distriktpsykiatriske sentre

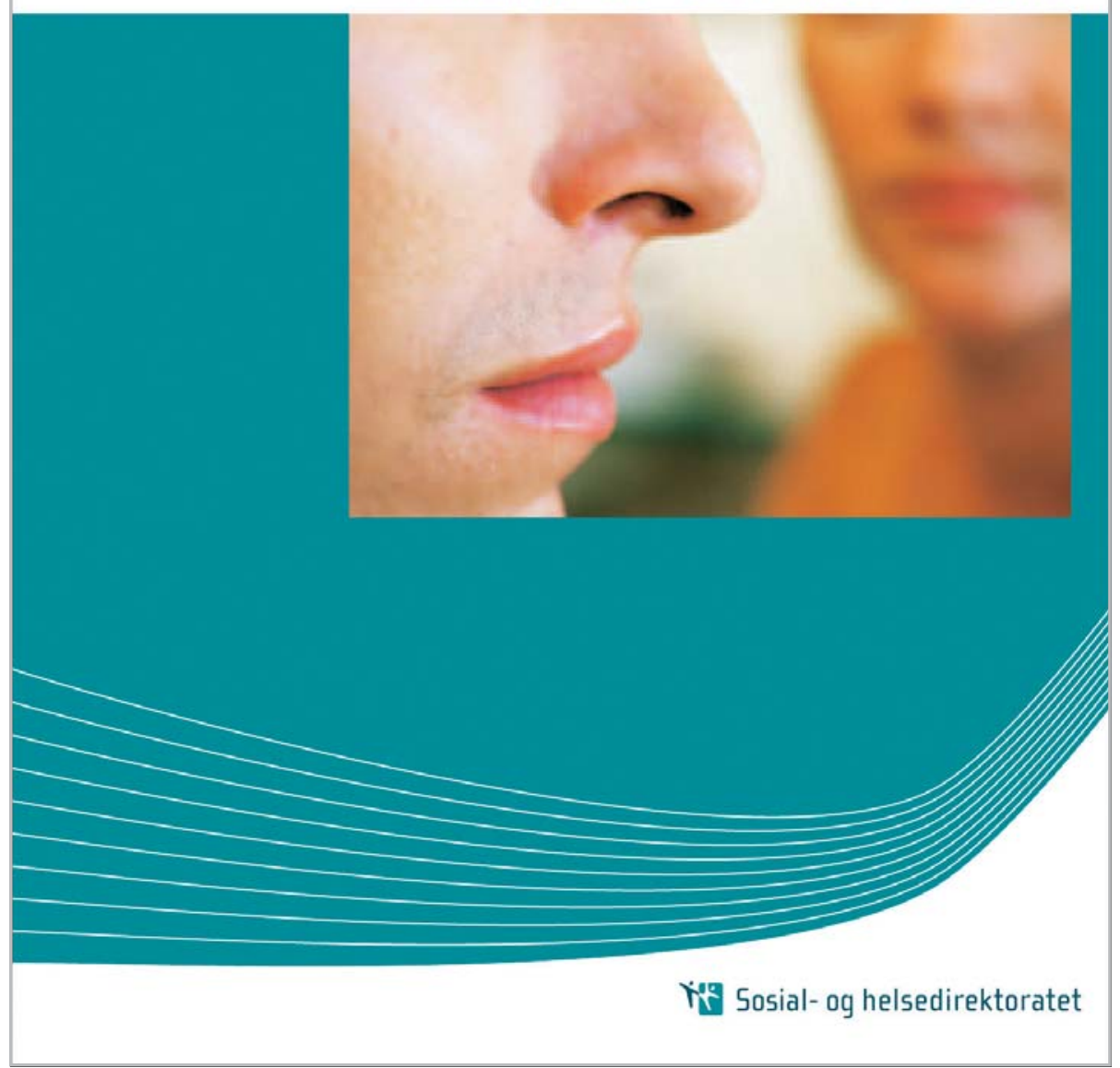

Tredje trinn handler om å abstrahere de enkelte meningsbærende enhetenes innhold i kondensater. Til slutt skal betydningen av dette sammenfattes til nye beskrivelser (Malterud, 2011). Studien er godkjent av NSD (Norsk Samfunnsvitenskapelig Datatjeneste). Informert samtykke er underskrevet av alle informanter.

\section{Funn}

En lesning av alle intervjuene for å få et helhetsinntrykk ga en forståelse av at alle informanter kjente til de nasjonale retningslinjene. Så mange som 70-80 prosent av sakene teamene behandlet var relatert til selvmordsproblematikk. Informantene opplevde seg trygge på å stille spørsmål til alle pasienter om de har eller har hatt selvmordstanker og om de tidligere har fors $\varnothing \mathrm{kt}$ å ta sitt liv. 
Ingen hadde opplevd å være involvert i en tilsynssak fra helsetilsynet fordi de personlig hadde utført kritikkverdig selvmordsrisikohåndtering. De arbeidet alltid to og to sammen. Ved analyse av intervjuene utkrystalliserte tre overordnete temaer seg som sentrale i beskrivelsene av de tre teamenes selvmordsforebyggende praksis. Disse temaene var: Grenseoppganger mellom kartlegging og vurdering av selvmordsrisiko, behovet for dokumentering og nødvendigheten av opplæring. Teamene deles tilfeldig inn i gruppe $\mathrm{A}, \mathrm{B}$ og $\mathrm{C}$.

\section{Grenseoppganger mellom kartlegging og vurdering av selvmordsrisiko}

I analysen av de tre teamene ble denne overskriften om grenseoppganger utviklet - en sammenfatning av en kodegruppe hvor de meningsbærende enhetene omhandlet ulik praksis ved utføring av kartlegging og vurdering av selvmordsrisiko. Informantene i gruppe A gir klart inntrykk av at de er enige om at det ikke eksisterer noen uttalt kløft mellom hvem som får kartlegge og vurdere selvmordsrisiko:

Det har ikke vært noe veldig sånn fokus på teamet her egentlig mellom kartlegging og skille mellom det og vurdering. Hvem som kan gjøre hva. For det blir jo diskutert i en del miljøer. Hvem som har kompetansen til a vurdere. Sykepleier og sånn treårig som oss kan få lov til å kartlegge, men vi kan ikke få lov til å vurdere og sånt. Men det er jo ikke noe tema her egentlig.

Teamet hadde fast ansatte psykologer. Legevakt ble benyttet ved behov.

Team B informerte om at sykehusets interne prosedyrer ikke var i samsvar med retningslinjene, og at teamet opplevde dette som utfordrende:

Hvis vi skal følge disse sykehusrutinene til punkt og prikke, så skal det ikke være mer enn én risikofaktor. Hvis det bikker over i to, så må vi kople på en lege/psykolog. Og den dropper vi jo $i$ hele tiden.

På kveldstid og i helger hadde teamet ikke tilgang til de fast ansatte psykologer og lege. Det var da de ofte gjorde vurderinger som de følte seg trygge på.
De kunne benytte legevakt på kveldstid og i helger. Dette gjorde de sjelden, og tok heller sakene opp med teamets psykologer og lege i for- eller etterkant, på dagtid ved behov. På dagtid var teamets psykologer og lege også med ut til pasientene.

Team C mente at de på bakgrunn av lang fartstid hadde kompetanse til å gjøre vurdering av selvmordsrisiko, men informantene sa at de ikke $\varnothing$ nsket dette ansvaret.

Nei, jeg vil ikke ha det ansvaret. Men - jeg har kompetanse til det. Alle som sitter her har det.

De andre informantene bekreftet dette. Derfor benyttet de legevakt og vaktfunksjon på egen poliklinikk ved alle vurderinger. Teamet hadde ingen ansatt lege eller psykolog. En overlege kom innom en time i uken slik at teamet kunne legge frem saker til drøfting. Ekstravakter uten opplæring hadde blitt sendt ut ved enkelte anledninger uten faste ansatte for å møte potensielt selvmordstruede mennesker. Informantene var bekymret for dette og mente det ikke var forsvarlig.

\section{Behovet for dokumentering og nødvendigheten av opploering}

Alle tre teamene var gjennomgående opptatt av dokumentering av selvmordsrisiko og opplæring.

Materialet hadde en overvekt av meningsbærende enheter om temaene som utviklet disse sammenfatningene ved analyse av to kodegrupper. Av hensyn til begrensning av artikkelens omfang presenteres her kort hovedtrekkene fra hvert tema samlet:

Team A opplyste at de hadde en sertifiseringsordning. Dette innebar at alle ansatte sikres at de har vært giennom et visst antall moduler med opplæring på dette området, blant annet skal de gjennomføre mester-/svennopplæring i tre saker, ha godkjenning av tre journaler, gjennomføre kurs i selvmordsrisikoundervising, et kurs om etterlatte, og fem timer med diskusjon knyttet til videoen "Tid for liv". Informantene var enige om at de mente at retningslinjene hadde ført til et kvalitetsskille når det gjaldt journal- føring, i retning av det bedre. Det var rutine at enheten flere ganger i halvåret hadde fagm $\varnothing$ te hvor et journalnotat ble vist i plenum og diskutert. Informantene opplevde at dette skapte kunnskap og trygghet i forhold til nye vurderinger.

Hos team B måtte alle gjennomføre kurs hos spesialist i selvmordsrisikovurderinger. De hadde også et fadderprogram for nyansatte hvor det blant annet ble gjennomført mester-/svennopplæring med fokus på både pasientkontakt og journalføring. Teamet hadde også, som team A, fagmøte med drøfting av journalnotater i plenum.

Team C hadde først begynt med obligatorisk undervisning i $2011 \mathrm{i}$ form av et tretimerskurs. Dette var utløst av en tilsynssak der DPS-et fikk kritikk.

Fadderordning for nyansatte ble startet i 2009, men denne hadde ikke spesielt fokus på selvmordsrisikohåndtering. Det var ingen spesiell opplæring i dokumentasjon, og det ble gjort ulikt. De uttrykte $\varnothing$ nske om st $\varnothing$ rre likhet og opplæring i journalføringen.

\section{Diskusjon}

En svakhet med studien er at alle intervjuer og analyser er utført av forfatteren alene. Et intervju foregikk på forskerens egen arbeidsplass, og dette kan ha påvirket dataene. Kliniske retningslinjer skal bidra til å redusere gapet mellom evidensbasert forskning og praksis (Ploeg et al., 2007). Evidensbasert praksis innebærer at det legges til rette for at klinikeren har et mest mulig solid og oppdatert grunnlag å basere kliniske beslutninger på (Walby, 2003). En vellykket implementering krever forankring i ledelsen (Ness, 2009). Studien viser tydelig dette; team C, som har hatt manglende ledelsesforankring av retningslinjene, har også hatt minst opplæring i praksis og journalføring. At ekstravakter uten opplæring sendes ut alene er i direkte strid med retningslinjene (Sosial- og helsedirektoratet, 2008). At informantene opplevde dette som uforsvarlig er forståelig. Team B opplevde diskrepans mellom interne prosedyrer og de nasjonale retningslinjene, fordi lokale prosedyrer ikke var oppdatert i tråd med retningslinjene. 
Det ble uklart hvilke retningslinjer som gjaldt, de nasjonale eller de lokale? I studier bekreftes det at implementering av retningslinjer må ta høyde for barrierer helt ned til den enkelte utøver (Ploeg et al., 2007). Man har tendens til å undervurdere implementeringsarbeidet med nye retningslinjer, noe praksisen i team $\mathrm{B}$ viste. Metodikken med å revidere journaler i plenum ga $\varnothing \mathrm{kt}$ trygghet og kompetanse. Team C, som ikke fikk dette, savnet opplæring i dokumentasjon.

Alle teamene som ble intervjuet mente at de hadde kompetanse til å vurdere selvmordsrisiko. Herrestad og Larsen (2012) foreslår at annet personell skal ha forskningsbasert kunnskap om selvmord, lang klinisk erfaring med selvmordsrisikovurderinger og veiledning av psykologer eller leger. Informantene hadde lang klinisk erfaring, men det var usikkert hvor mye de benyttet veiledning av leger og psykologer når de skulle gjøre vurderinger. Kun ett team sa at de alltid gjorde det. I hvilken grad de hadde kjennskap til forskningsbasert kunnskap om selvmord er usikkert. Det ene teamet opplyste at de var sertifiserte. Dette gir de ansatte trygghet i forhold til at ledelsen har tatt ansvaret for å innføre rutiner som sikrer kompetanse og ansvarlighet $i$ tråd med kravene fra de nasjonale retningslinjene. Dette er intern kontroll. Hvorvidt dette innebar at de faktisk hadde tilstrekkelig kompetanse, er vanskelig å vite. En revisjon vil kunne avdekke dette. Alle tre akutteamene har besluttet at de alltid skal være to som unders $\varnothing$ ker pasientene, noe som kan $\varnothing$ ke kvaliteteten på vurderingene, og dermed kompetansenivået (Johnson et al., 2008). Teamene hadde i varierende grad tilknyttet lege og psyko$\log$. Team $C$ hadde kun veiledning av overlege en time i uken. Team A og B hadde leger og psykologer ansatt $i$ teamene og drøftet alle sakene hver dag. Det sier seg selv at dette gir betydelig forskjell i kvalitetssikringen av vurderingene.

\section{Konklusjon}

Hovedfunnet i denne studien er at det var store variasjoner i den selvmordsforebyggende praksis blant de tre unders $\varnothing$ kte DPS akutteam i forhold til implementering av de nasjonale retningslinjene.
Dette gjaldt kartlegging og vurdering av selvmordsrisiko, opplæring, dokumentasjon, ledelsesforankring og veiledning av leger og psykologer. Et team sendte ut ekstravakter uten opplæring, noe som er i strid med retningslinjene. Alle informanter kartla selvmordsrisiko og alle mente at fokus på dokumentasjon var styrket. Ett av tre team hadde en egen sertifiseringsordning som sikret kravet til kompetanse hos høyskoleutdannet helsepersonell for å vurdere selvmordsrisiko. De andre teamene hadde ikke noe tilsvarende, og et team opplevde direkte dissens mellom interne prosedyrer og retningslinjene. Dette kan være en konsekvens av en manglende nasjonal definisjon på hvilken reell kompetanse annet personell enn leger og psykologer må ha for å vurdere selvmordsrisiko.

Funnene i denne studien kan være relevante for lignende team og personell som arbeider med selvmordsforebyggende praksis innenfor psykisk helsevern i Norge.

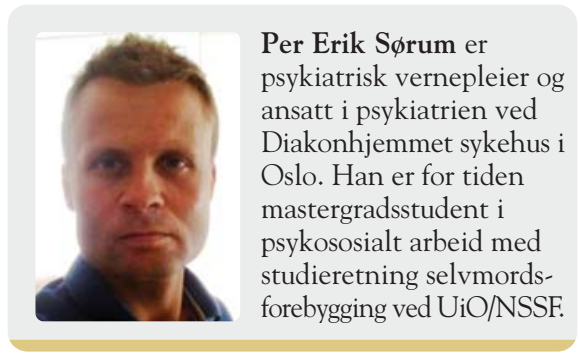

\section{Referanser}

Burns, T. (2004). Community mental health teams. A guide to current practices. New York: Oxford University Press.

Cavanagh, J.T.O., Carson, A., Sharpe, M., \& Lawrie, S. (2003). Psychological autopsy studies of suicide: a systematic review. Psychological Medicine; 33 (3): 395-405.

Giorgi, A. (2009). The descriptive phenomenlogical method in psychology: A modified Husserlian approach. Pittsburg, PA: Duquesne University Press.

Hasselberg, N., Gråwe, R.W, Johnson, S., \& Ruud, T. (2011). Treatment and outcomes of crisis resolution teams: a prospective multicentre study. BMC Psychiatry; 11: 183.

Herrestad, H. \& Larsen, K. (2012). Kartlegging, observasjon og vurdering av selvmordsrisiko. RVTS$\emptyset$ st. Lest 13.01.12. (http://ost.rvts.no/Images/assets/ dokuments/ost/vurdering $\% 20$ av\%20selvmordsrisiko\% 20jan2012.pdf)

Johnson S., Needle, J., Bindman, J.P., \& Thornicraft, G. (2008). Crisis Resolution and Home Treatment in Mental Health. Cambridge: Cambridge University Press.
Karlsson, B., Borg, M., Eklund, M., \& Hesook, K.I (2011b). Profiles of and practices in crisis resolution and home treatment teams in Norway: a longitudinal survey study. International Journal of Mental Health Systems; 5:19. Lest 09.03.12: http://www.ijmhs.com/content/5/1/19

Karlsson, B., Borg, M., \& Sjølie, H. (2011a). En kartleggingsstudie: Ambulante akutteam ved distriktspsykiatriske sentre. Sykepleien forskning; 1 (6): 62-68.

Kitzinger, J. (1985). Qualitative Research: Introducing focus groups. BMJ; 311:299.

Malterud, K. (2011). Kvalitative metoder i medisinsk forskning. En innføring. 3. utgave. Oslo: Universitetsforlaget.

Muusman \& Agenda. (2008) Kartlegging av de Distriktspsykiatriske sentrene i Norge 2008 RAPPORT. AGENDA Utredning \& Utvikling AS. Lest 28.10.11. (http://www.helsedirektoratet.no /vp/multimedia/archive/00080/Kartlegging_av_de_ Di_80869a.pdf)

Ness, E. (2009). Opplæringsstrategi for å underst $\varnothing t t e$ de nasjonale retningslinjene for selvmordsforebygging. Suicidologi; 14 (1): 8 .

Ploeg, J., Davies, B., Edwards, N., Gifford, W., \& Miller, P.E. (2007). Factors Influencing Best-Practice Guideline Implementation: Lessons Learned from Administrators, Nursing Staff, and Project Leaders. Worldviews on Evidence-Based Nursing; 4 (4): 210-219.

Ruud, T., Gråwe, R.W., \& Hatling, T. (2006). Akuttpsykiatrisk behandling i Norge - resultater fra en multisenterstudie. (SINTEF A310) Oslo: SINTEF Helse.

Sosial- og helsedirektoratet. (2006). "Du er kommet til rett sted ........." Ambulante tjenester ved distriktspsykiatriske sentre. (IS 1358/2006). Oslo: Sosial- og helsedirektoratet.

Sosial- og helsedirektoratet. (2008). Nasjonale retningslinjer for forebygging av selvmord i psykisk helsevern. (IS 1511/2008). Oslo: Sosial- og helsedirektoratet.

Statens helsetilsyn. (2006). Tilsynsmelding 2006. Oslo: Statens helsetilsyn. Lest 11.01.12. (http://www. helsetilsynet.no/upload/Publikasjoner/tilsynsmeldi ng/tilsynsmelding2006.pdf)

Statistisk sentralbyrå. (2010). Dфdsårsaker: tabell 1: D $\phi$ dsfall etter årsak. Hele landet. 1991-2010. Oslo: Statistisk sentralbyrå. Lest 25.10.11. (http:// www.ssb.no/emner/03/01/10/dodsarsak/tab-2011-10 14-01.html)

Stortingsproposisjon nr. 1 (2004-2005). Statsbudsjettet for 2005. Oslo: Finansdepartementet.

Tjora, A. (2010). Kvalitative forskningsmetoder i praksis. Oslo: Gyldendal.

Walby, F.A. (2003). Evidensbasert psykoterapi: en metode for kliniske beslutninger - ikke et forskningsdesign. Impuls, tidsskrift for psykologi. 57 (1): 85-91.

Wibeck, W. (2010). Fokusgrupper. Om fokuserade gruppintervjuer som undersökningsmetod. Lund: Studentlitteratur AB. 